\title{
The Attractiveness of Reversing Teaching Forms Feedback on an Electrical Engineering Course
}

\author{
https://doi.org/10.3991/ijep.v10i3.12361
}

\author{
Sébastien Jacques $\left({ }^{\bowtie}\right)$, Thierry Lequeu \\ University of Tours, Tours, France \\ sebastien.jacqueseuniv-tours.fr
}

\begin{abstract}
The transformation of teaching practices in universities remains necessary to better motivate, involve and promote the success of increasingly "connected" students. These new practices can be off-putting to teachers because of the complexity of their implementation. New practices, such as those in the inverted/flipped classroom model, which consists of reversing the nature of inclassroom and out-of-class activities, are well documented in the pedagogical literature; however, few empirical studies are available that allow us to objectively analyze their effect on student learning. As such, university teachers are not being encouraged to change their traditional pedagogical practices. This manuscript proposes a rather simple method, which draws on but is not directly equivalent to the inverted classroom model. The aim here is to reverse the traditional pedagogical sequence of "Lectures; Tutorials; then Practical work". This mode of teaching is still very popular in the university system, particularly in France. More precisely, in the proposed model, teaching begins with practical work, followed by tutorials and finishing with lectures that offer time for questions and debates. This method places much more importance on collaborative working and the consolidation of students' knowledge and skills. An online course platform called Celene has been widely used to support student learning and to maximize teacher-learner interactions. The proposed approach was tested with students of an electrical engineering course in their final year of engineering school. A full six-year feedback period is discussed to demonstrate the interactivity and effectiveness of the approach. The results of the various experiments carried out show that this method "smooths" out some of the difference in student competence. In particular, it is a powerful remediation approach to restore energy to students, who sometimes feel overwhelmed by the traditional approach, which is very transmissive. As a result, the proposed method significantly reduces failure rates.
\end{abstract}

Keywords - Attractiveness of education, higher education, reversing teaching forms, electrical engineering curriculum.

\section{Introduction}

Over the past few decades, many papers have denounced the use in universities of pedagogy based on overly transmissive methods, which are described as traditional, 
and where lectures are part of the university tradition [1-3]. In this configuration, teaching is considered to take place in a linear progression. All teaching/learning activities are focused on the teacher, who must master all the appropriate pedagogical mechanisms, processes and methods. Thus, everything is designed in such a way as to remove the possibility of error completely. This traditional method can be very effective when the teacher can maintain the students' attention, concentration and motivation. In terms of evaluation, this method aims to measure a learner's ability to reproduce as accurately as possible what has been taught and to apply it in situations similar to those previously studied.

Generation $\mathrm{Z}$ (Gen $\mathrm{Z}$ ), i.e. the generation that grew up with the Internet and takes full advantage of new technology, is now entering higher education with expectations, demands and aspirations that are completely different to those of previous generations [4]. The significant deployment of new information and communication technologies (ICTs) has led to a change in the pedagogical model [5]. Students are no longer spectators to their own learning, but, on the contrary, active participants. ICTs can offer members of Gen $\mathrm{Z}$ detailed answers to all their questions in a matter of a few clicks of a mouse or swipes of a finger. In higher education, these young people wish to be at the heart of knowledge; they desire to communicate, interact and contribute to exchanges rather than passively receive and absorb information. As such, it is clear that the traditional pedagogical method, which revolves around the lecture format, is of little interest to them. Teaching Digital Natives, who have grown up in a digital world, can feel something like completing a jigsaw puzzle. It is therefore important that teachers try to understand and, above all, question new pedagogical practices before implementing them [6].

In recent years, new and effective teaching strategies have been the subject of much discussion in the literature [7-16]. Such practices include, but are not limited to, the following:

1. Inverted/Flipped classroom: This approach involves asking learners to study educational content before the classroom session, either in digital format (i.e., videos, ebooks, slideshows, websites etc.) or in printed format (i.e., books, handouts etc.), and to spend time in class on exercises, projects and/or discussions. This method is widely used in the United States and Canada [7-8]. Its main proponents are Eric Mazur, Jonathan Bergmann, and Aaron Sams. The method has also been extended to Europe and in particular to Germany where Falko Peschel is one of its leading proponents.

2. Active learning: The purpose here is to allow students to engage with the material, participate in the classroom and collaborate with each other. This concept is largely inspired by important figures in the New Education Movement, such as John Dewey, Rudolf Steiner, Maria Montessori, Edouard Claparède, Janusz Korczak, and Célestin Freinet [9]. It helps students develop as they progress through each stage of Bloom's taxonomy (see Figure 1) [10]. 
3. Problem-based learning (PBL): This is a student-centered approach where students learn about a subject by understanding and solving problems [11-15]. The PBL process was developed by Howard S. Barrows and Robyn M. Tamblyn in the 1960s as part of the medical program at McMaster University in Hamilton, Canada.

4. Blended learning: This method uses traditional classroom instruction combined with online learning and independent study. It is widely agreed that the rise of the Internet in the 1990s allowed blended learning to flourish [16]. The Web has provided training specialists with a variety of new opportunities to interact with learners, including: traditional training, e-learning modules; online tutoring; virtual coaching; mobile checklists; webinars; and social learning platforms, among others.

Although there are many practices, developing a teaching strategy that is acceptable to the greatest number of people is not so easy. This process includes the planning of all the specific pedagogical methods and means that will be used to achieve the learning objectives of a given course in a given subject, at a given academic level and for a specific cohort of students.

This paper proposes an evaluation of the impact of changing the traditional course procedure: "Lectures; Tutorials; then Practical work". This traditional sequence is widely deployed in engineering schools, particularly in France. The objective is to reverse this traditional order. This means that students start learning through practical work, followed by tutorials to directly address the issues of the professional environment. These practical activities and case studies, which are carried out in small groups, make it possible to create real situations that trigger a desire in students to involve themselves fully in the learning process. The teaching ends with lectures that are not like the traditional model where the teacher is called upon to share his or her knowledge. On the contrary, they are based on a question/debate approach. The proposed strategy does not use an inverted classroom model, in the sense that students are not asked to go in search of knowledge before coming to class. The difficulties of the inverted classroom model are related to the provision of resources that offer the knowledge that needs to be acquired by the students and ensuring that these resources are used. In the proposed method, practice becomes predominant and students are expected to use such materials and collaborate with each other.

The concrete application of collaborative work allow students to better consolidate their knowledge and skills. The lecture becomes, for its part, an exercise in synthesis based on feedback rather than the dry presentation of a knowledge set to digest. Thus, it makes it possible to define methods and tools for solving concrete problems, even if they are only partially defined. The proposed method, which is quite simple to implement, remains stimulating for the students because they get to work on concrete cases; but it also gives a central role to the teacher who must be prepared to conduct the process. This method is discussed in terms of how it was applied as part of a final year course at an engineering school in electrical and electronic engineering; the course usually has a high failure rate when the traditional approach is used.

This paper serves a number of purposes. Section 2 gives background about the study. The objective is to justify the use of the proposed pedagogical method based on an exhaustive analysis of students' feelings about the move away from the more traditional 
approach. The methodological aspects of this study are described in Section 3. Section 4 presents the main results and highlights the relevance of the method of reversing the teaching procedure compared to the traditional university pedagogical approach

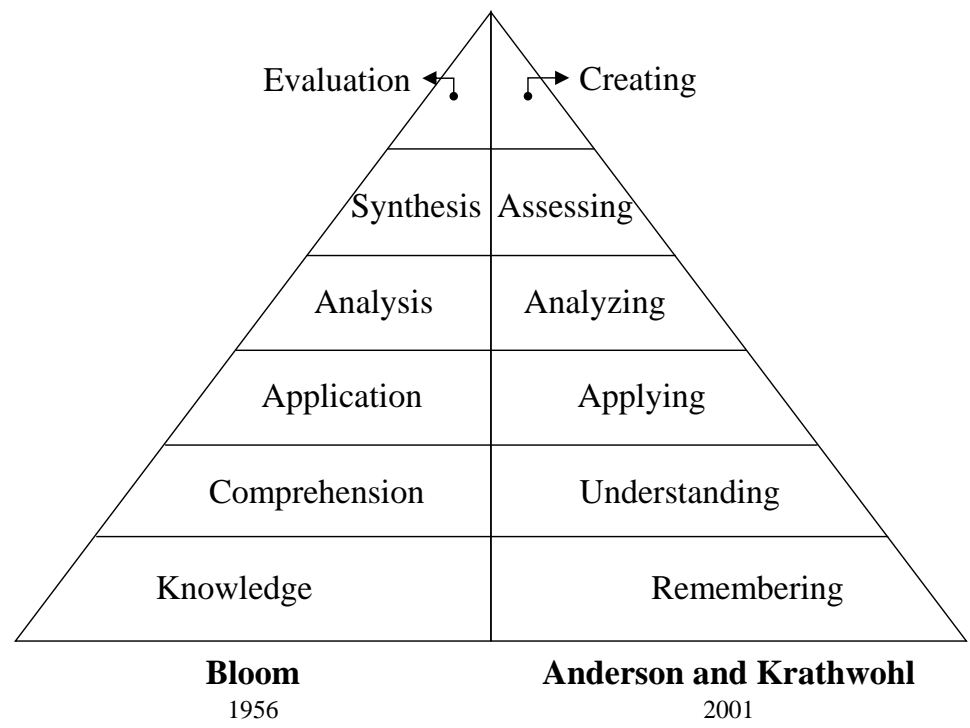

Fig. 1. Bloom's taxonomy [10]

\section{Background of the Study}

\subsection{Student training and choice of course for the experiment}

The study proposed in this manuscript was carried out with students in electrical and electronic engineering at a French engineering school (the College of Engineering at the University of Tours). The "Electronics and Electrical Energy Systems" component of the engineering degree trains future engineers (theoretical capacity of 30 engineering students per class) in design and in-depth understanding of electronic systems [17]. The curriculum follows a systems analysis approach, offering many concrete examples, both in terms of energy efficiency and electrical energy optimization. For each of the three years of the engineering program, the courses are grouped into five units of approximately 80 hours each.

We are particularly interested here in the component entitled "Electrical Energy Conversion". This unit aims to provide students with the tools and methods to design electrical energy conversion systems, covering material ranging from design to planning and development to implementation in industrial systems. In terms of the competency framework, this teaching unit contributes to the assessment of a key competency in the ability to mobilize resources in a specific scientific and technological field. The 
required level of "expertise" is that expected at the end of the last year of the engineering degree. In particular, with regard to the curriculum on electronics and electrical energy systems, students must master the sizing of electrical energy systems and be able to take into account the possible constraints of sustainable development.

In this article, we focus on one of the subjects that make up the "Electrical Energy Conversion" teaching unit. This is a course on power devices and their industrial applications (i.e., electric vehicle applications). At the end of this course, students must master the following three skills:

1. Be able to define appropriate criteria for the selection of a power device according to the requirements of a target application.

2. Be able to better understand the parasitic elements of the physical structure of a power component.

3. Be able to implement appropriate methods of protecting a power device (e.g., protection against overvoltage, overload, over-temperature, etc.).

This course requires prior knowledge of physics of semiconductor devices and power electronics (static power converters).

In its traditional form, this course consists of 12 hours of lectures, 8 hours of tutorials and 16 hours of practical work. This is a course considered difficult by students has a high failure rate. We will take a closer look at the feelings of students about this course who followed this traditional approach.

\subsection{Students' feelings about the traditional approach to teaching}

The traditional form of the course on power devices and their applications was evaluated in 2013 and 2014. Table 1 summarizes the results of student responses to a questionnaire prepared by the University of Tours. This questionnaire was developed using a software platform (EvaSys) to automate the evaluation process of the engineering curriculum. This software tool saves considerable time at all stages of the evaluation process: from survey design to distribution, reporting and accuracy of automatically generated data.

The results in Table 1 show that the traditional form of teaching applied to this course has four main weaknesses listed in questions 4), 5), 7), and 9). In fact, the results are almost the same for the two cohorts that responded to the survey.

The major point noted by the students (see the results of question 5)) is that the traditional form of teaching is not very stimulating (i.e., about $60 \%$ of satisfied students regardless of class). The students interviewed denounce the fact that they are not sufficiently involved, particularly in courses and tutorials, even if the latter are considered clearly structured.

Respondents are not entirely convinced by teaching and supported materials used (see the results of question 4)). Indeed, about $66.5 \%$ of the engineering students were satisfied regardless of class. These people considered that there was too much information to digest. 
Although students consider the time allocated to practical work to be appropriate, they find it too far from the lectures. According to them, this practical time is essential to identify a common thread to follow in order to validate the required skills.

Table 1. Summary of the satisfaction survey (Likert scaling). The results for the 2013 class (26 students completed the survey) and the 2014 class ( 23 students completed the survey) are shown in blue and green respectively.

\begin{tabular}{|c|c|c|c|c|c|c|c|}
\hline Question & $\mathrm{TD}=1$ & $D=2$ & $A=3$ & $\mathbf{T A}=4$ & Mean & $\begin{array}{l}\text { Standard } \\
\text { deviation }\end{array}$ & \begin{tabular}{|c|} 
Satisfaction \\
score
\end{tabular} \\
\hline $\begin{array}{l}\text { 1. The program of this teaching } \\
\text { was clearly introduced. }\end{array}$ & $\begin{array}{l}0.0 \% \\
4.0 \% \\
\end{array}$ & $\begin{array}{c}8.0 \% \\
17.0 \% \\
\end{array}$ & $\begin{array}{l}46.0 \% \\
48.0 \% \\
\end{array}$ & $\begin{array}{l}46.0 \% \\
30.0 \% \\
\end{array}$ & $\begin{array}{l}3.38 \\
3.02 \\
\end{array}$ & $\begin{array}{l}0.6 \\
0.8\end{array}$ & $\begin{array}{l}84.5 \% \\
75.5 \% \\
\end{array}$ \\
\hline $\begin{array}{l}\text { 2. The prerequisites for this } \\
\text { teaching were clearly pre- } \\
\text { sented. }\end{array}$ & $\begin{array}{l}12.0 \% \\
0.0 \%\end{array}$ & $\begin{array}{l}12.0 \% \\
27.0 \%\end{array}$ & $\begin{array}{l}46.0 \% \\
45.0 \%\end{array}$ & $\begin{array}{l}31.0 \% \\
27.0 \%\end{array}$ & $\begin{array}{l}2.94 \\
2.97\end{array}$ & $\begin{array}{l}1.0 \\
0.8\end{array}$ & $\begin{array}{l}73.5 \% \\
74.3 \%\end{array}$ \\
\hline $\begin{array}{l}\text { 3. The content of this teaching } \\
\text { was adapted to your } \\
\text { knowledge. }\end{array}$ & $\begin{array}{l}15.0 \% \\
9.0 \%\end{array}$ & $\begin{array}{c}8.0 \% \\
13.0 \%\end{array}$ & $\begin{array}{l}58.0 \% \\
52.0 \%\end{array}$ & $\begin{array}{l}19.0 \% \\
26.0 \%\end{array}$ & $\begin{array}{l}2.81 \\
2.95\end{array}$ & $\begin{array}{l}0.9 \\
0.9\end{array}$ & $\begin{array}{l}70.3 \% \\
73.8 \%\end{array}$ \\
\hline $\begin{array}{l}\text { 4.Teaching and supporting ma- } \\
\text { terials were sufficient and ap- } \\
\text { propriate. }\end{array}$ & $\begin{array}{l}8.0 \% \\
4.0 \%\end{array}$ & $\begin{array}{l}35.0 \% \\
50.0 \%\end{array}$ & $\begin{array}{l}42.0 \% \\
20.0 \%\end{array}$ & $\begin{array}{l}15.0 \% \\
26.0 \%\end{array}$ & $\begin{array}{l}2.64 \\
2.68\end{array}$ & $\begin{array}{l}0.8 \\
0.8\end{array}$ & $\begin{array}{l}66.0 \% \\
67.0 \%\end{array}$ \\
\hline $\begin{array}{l}\text { 5.This teaching was presented } \\
\text { in a stimulating and motivating } \\
\text { way. }\end{array}$ & $\begin{array}{c}8.0 \% \\
10.0 \%\end{array}$ & $\begin{array}{l}52.0 \% \\
52.0 \%\end{array}$ & $\begin{array}{l}36.0 \% \\
14.0 \%\end{array}$ & $\begin{array}{l}4.0 \% \\
24.0 \%\end{array}$ & $\begin{array}{l}2.36 \\
2.42\end{array}$ & $\begin{array}{l}0.7 \\
0.9\end{array}$ & $\begin{array}{l}59.0 \% \\
60.5 \%\end{array}$ \\
\hline $\begin{array}{l}\text { 6. The coordination between } \\
\text { the lectures, tutorials and prac- } \\
\text { tical works was stimulating. }\end{array}$ & $\begin{array}{l}4.0 \% \\
4.0 \%\end{array}$ & $\begin{array}{l}0.0 \% \\
9.0 \%\end{array}$ & $\begin{array}{l}64.0 \% \\
57.0 \%\end{array}$ & $\begin{array}{l}32.0 \% \\
30.0 \%\end{array}$ & $\begin{array}{l}3.24 \\
3.13\end{array}$ & $\begin{array}{l}0.7 \\
0.8\end{array}$ & $\begin{array}{l}81.0 \% \\
78.3 \%\end{array}$ \\
\hline $\begin{array}{l}\text { 7. The illustrations (i.e., exer- } \\
\text { cises, case studies, and practi- } \\
\text { cal works) were sufficient. }\end{array}$ & $\begin{array}{l}12.0 \% \\
5.0 \%\end{array}$ & $\begin{array}{l}38.0 \% \\
48.0 \%\end{array}$ & $\begin{array}{l}23.0 \% \\
19.0 \%\end{array}$ & $\begin{array}{l}27.0 \% \\
28.0 \%\end{array}$ & $\begin{array}{l}2.65 \\
2.70\end{array}$ & $\begin{array}{l}1.0 \\
0.8\end{array}$ & $\begin{array}{l}66.3 \% \\
67.5 \%\end{array}$ \\
\hline $\begin{array}{l}\text { 8. Instructions for preparing } \\
\text { knowledge assessments were } \\
\text { clear. }\end{array}$ & $\begin{array}{l}15.0 \% \\
14.0 \%\end{array}$ & $\begin{array}{c}19.0 \% \\
5.0 \%\end{array}$ & $\begin{array}{l}46.0 \% \\
64.0 \%\end{array}$ & $\begin{array}{l}20.0 \% \\
18.0 \%\end{array}$ & $\begin{array}{l}2.71 \\
2.86\end{array}$ & $\begin{array}{l}1.0 \\
0.9\end{array}$ & $\begin{array}{l}67.8 \% \\
71.5 \%\end{array}$ \\
\hline $\begin{array}{l}\text { 9. You feel well prepared for } \\
\text { knowledge assessments. }\end{array}$ & $\begin{array}{l}32.0 \% \\
12.0 \% \\
\end{array}$ & $\begin{array}{l}28.0 \% \\
41.0 \% \\
\end{array}$ & $\begin{array}{l}24.0 \% \\
27.0 \% \\
\end{array}$ & $\begin{array}{l}16.0 \% \\
20.0 \%\end{array}$ & $\begin{array}{l}2.24 \\
2.55 \\
\end{array}$ & $\begin{array}{l}1.1 \\
0.9 \\
\end{array}$ & $\begin{array}{l}56.0 \% \\
63.8 \% \\
\end{array}$ \\
\hline
\end{tabular}

TD: totally disagree. D: disagree. A: agree. TA: totally agree.

All these elements do not allow students to take their exams with confidence. According to the results of question 9), about $60 \%$ of survey respondents on average over the two classes considered felt that they did not feel prepared for the various knowledge tests.

Despite the negative points listed above, the results in Table 1 also show that coordination between lectures, tutorials and practical work (see the results of question 6)) is considered satisfactory (i.e., about $80 \%$ of satisfied students regardless of class). This raises the question of whether reversing pedagogical forms can help to solve the various problems listed above. Thus, in this manuscript, we propose to test a pedagogical method consisting in starting the teaching with practical work and tutorials, then ending with a synthesis of the main ins and outs; the synthesis carried out during the hourly volume allocated to the lectures. This method, which is relatively easy to implement, allows students to be more involved and teachers to remain in a central role. 


\section{$3 \quad$ Methodology}

\subsection{Characteristics of student populations before the experience}

In this article, a comparative study was carried out on six classes of engineering students. The objective is to highlight the interest of the method of reversing teaching forms in relation to a traditional pedagogical approach. Two sizes of student cohort were studied: a group of less than 30 students (i.e., 2014 class, 2016 class, 2018 class, and 2019 class), and a group of more than 30 students (i.e., 2015 class, and 2017 class). These group sizes were not really chosen by the teacher, but they depend on the recruitment phase in the first year of the engineering curriculum. Students in the 2016, 2017, 2018 and 2019 classes followed the method of reversing teaching forms. The 2014 and 2015 groups followed the traditional sequence of teaching (i.e., Lectures; Tutorials; then Practical work).

It is important to note that the 2019 class is composed of only 13 students due to major pedagogical changes. Indeed, in the electrical and electronic engineering specialty, there are two possible academic programs: the first one in electronics and electrical energy systems and the second one, in electronics and autonomous embedded systems. The thirty students expected are now divided between these two programs. Thus, the results of the 2019 class are given, but they must be put into perspective given the small number of students who took the course on power devices and their applications.

Each group of students was evaluated before the beginning of the experience. The objective was to ensure that each cohort was at approximately the same level before the experience began. This point is fundamental in order to be able to compare the classes between them after the two proposed methods (i.e., traditional sequence of teaching, and method of reversing teaching forms).

The evaluation (i.e., multiple-choice questions), of an equivalent level for each group, focused on the prerequisites (i.e., 20 questions on physics of semiconductor devices, and 20 questions on static converters) for successful completion of the course.

Figure 2 shows the distribution of engineering students' local grades (from 0 to 20) in the different classes. An analysis using the normal probability plot (Henry diagram) was chosen here. This method consists of making a graphical adjustment in the form of a line applied to a sample of $n$ points (here, the students' local grades) defined by their abscissa (observed values) and ordinate (estimation of the corresponding values of the cumulative distribution function). If the $n$ points are aligned, the distribution is considered normal. The linearity of each distribution of local grades is checked by calculating the coefficient of determination (or R-squared) of the trend curve. The more this coefficient tends towards one, the more the curve is considered linear, confirming that the distribution is normal. The normal probability graph has the advantage of quickly verifying whether a data set follows a normal distribution without having to use the rigor of normality tests. Finally, it is easy to quickly read the mean and standard deviation of the data set (see Table 2). 


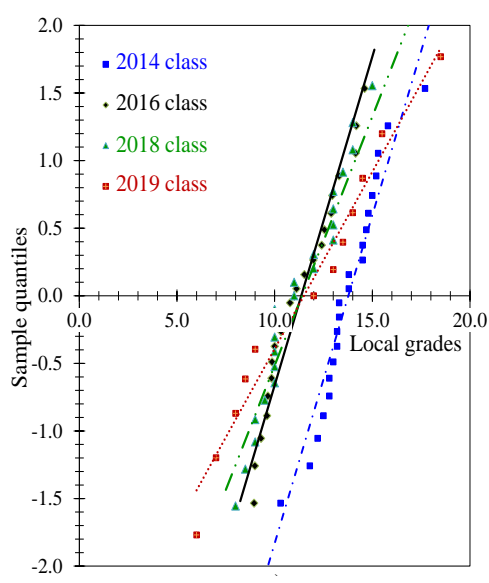

a) Groups of less than 30 students

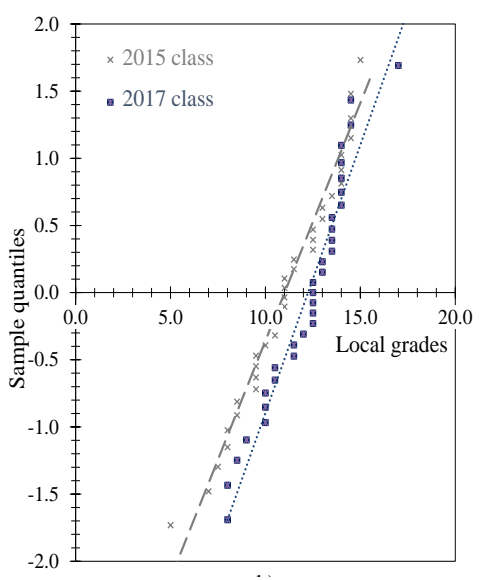

b) Groups of more than 30 students

Fig. 2. Characteristics of student populations before the teaching experience

Table 2. Characteristics of the normal probability plots

\begin{tabular}{|l|c|c|c|c|}
\hline & $\begin{array}{c}\text { Number of } \\
\text { students }\end{array}$ & $\begin{array}{c}\text { Mean (local } \\
\text { grade) }\end{array}$ & Standard deviation & $\begin{array}{c}\text { Coefficient of determna- } \\
\text { tion (R-squared) }\end{array}$ \\
\hline 2014 class & 24 & 13.77 & 2.06 & 0.96 \\
\hline 2015 class & 36 & 11.01 & 2.83 & 0.97 \\
\hline 2016 class & 24 & 11.36 & 2.06 & 0.96 \\
\hline 2017 class & 33 & 12.24 & 2.51 & 0.95 \\
\hline 2018 class & 25 & 11.40 & 2.72 & 0.92 \\
\hline 2019 class & 13 & 11.50 & 3.82 & 0.97 \\
\hline
\end{tabular}

According to the results in Figure 2 and Table 2, the different classes have almost the same behavior in terms of dispersion around the average value. Indeed, the standard deviation is about 2.5 , regardless of the size of the class. It can be noted that the average for the 2014 class is high compared to the other groups. For this class, the engineering school succeeded in recruiting very good students.

\subsection{Reversing teaching forms: Details of the method}

Figure 3 shows the principle of the method of reversing teaching forms. The latter is based on two software platforms. The first one consists in evaluating the relevance of the method via the EvaSys tool. The second, which is an online course platform called CELENE, allows interaction between teachers, learners and educational resources. In particular, teachers create pedagogical activities (e.g., platform's forum, quizzes, tests etc.). Students access the tool from any connected device during class and outside of class hours.

The reversing teaching sequence begins with practical work being carried out in a half-class. Firstly, the teachers present the course objectives through an already functional demonstrator; this demo board is representative of an industrial application. The 
objective is to create a pedagogical situation that triggers. From the demo board, the engineering students observe the main electrical signals to be obtained. The teacher then forms small groups of four students. These groups include both low- and highlevel students. Finally, the students must design and build their own demonstrator and perform experimental measurements of key quantities/signals to validate the planned stages of the practical work. The teacher establishes different milestones and deliverables to complete this stage of experimental measurements. Of course, he also gives students all the tips and tricks necessary to achieve the target objectives. Each group of students was required to keep a logbook throughout the practical work. The online course platform of the engineering school was especially dedicated to this purpose. This logbook was evaluated at the end of each session by the teacher, allowing students to know what they need to do in the next session and to give them tips on how to improve their level and skills. Finally, at the end of all practical work sessions, the engineering students had to validate an individual knowledge test. This was a case study that was close to the material studied during the tutorials.

The tutorials were conducted in the entire class. The students were divided into groups of eight people to continue to strengthen the proximity between students and teacher. The teacher was able to mix students from each practical working group. A concrete application was proposed to each small group. For students, the aim was to develop a better understanding of the most important physical concepts; concepts that had already been experimentally observed. They had to discuss together and agree on how to solve the various exercises given to them. The teacher managed the time allocated, suggested working methods, redirected group discussions where necessary and ensured everyone's participation. He did not solve the exercises for the engineering students. At the end of each tutorial, each group was required to submit an activity report via the online course platform. These reports were evaluated by the teacher before the beginning of the next session. Comments and suggestions for improvement were visible to all students. Finally, at the end of all tutorial sessions, the engineering students had to validate an individual knowledge test. This was a case study that was close to the material studied during the tutorials.

As for the lectures, the teacher identified inconsistencies in problem solving within each group and proposed key methods for solving problems. These methods, which were widely discussed by the students, were presented in the form of guidelines. Videos were used to complement and illustrate these different methods. These lecture sessions ended with a conference facilitated by an industry expert in the field with the objective of giving the students a business perspective. The teaching was finished off with a final written examination representative of a concrete industrial application. 


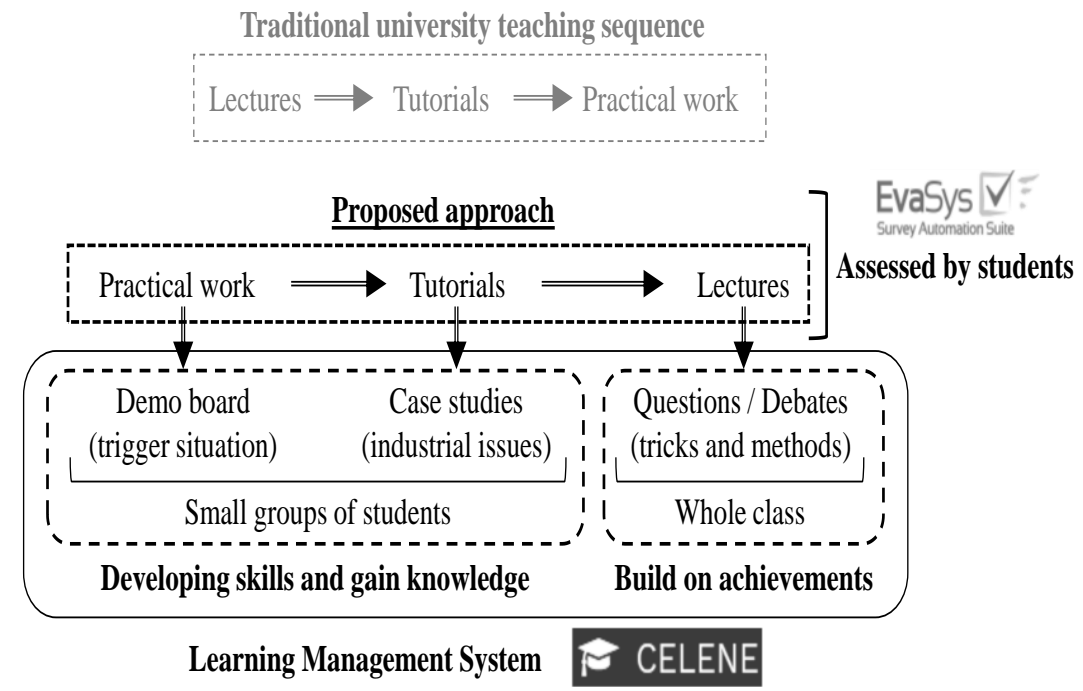

Fig. 3. Reversing teaching forms: details of the method

\section{$4 \quad$ Main Results and Discussion}

Figure 4 compares overall student achievement between the reverse teaching method and the traditional approach. A distinction was made between cohorts of less than thirty students (see Figure 4 a)) and those of more than thirty students (see Figure 4 b)). For each group of students, their performance is described in the form of a radar-type diagram. Each circle of a radar chart corresponds to a local grade (i.e., from 0 to 20). Therefore, it is hoped that the results of a given student cohort will be positioned at the highest possible grade (i.e., all around its corresponding circle). A non-circular trajectory indicates a dispersion of the results and therefore a standard deviation that should be as small as possible.

The results in Figure 4 show that the fluctuations around the mean value are far too large for groups of students who followed the traditional teaching method. For example, for the 2014 class, the standard deviation is about 2.6. In addition, too many students failed at the end of this course (e.g., nearly $58 \%$ for the 2015 class). Given the results in Table 1, the traditional form of teaching does not necessarily encourage weaker students to motivate themselves to achieve the expected competencies.

Although the reverse teaching form was introduced with the 2016 cohort onwards, the benefits of this method were not immediate and a break-in period was necessary. 


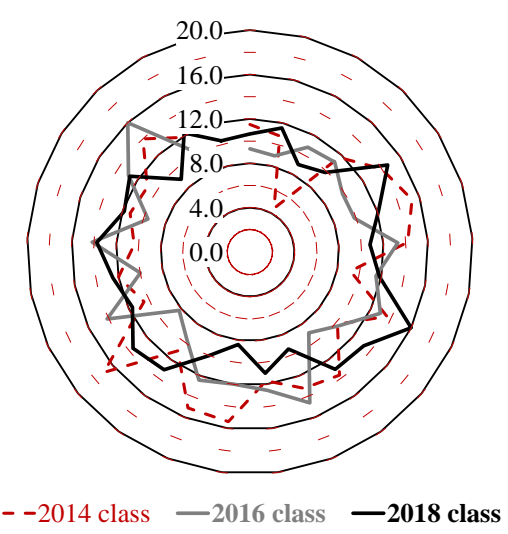

The 2016 and 2018 classes followed the method of reversing teaching forms

a) Groups of less than 30 students

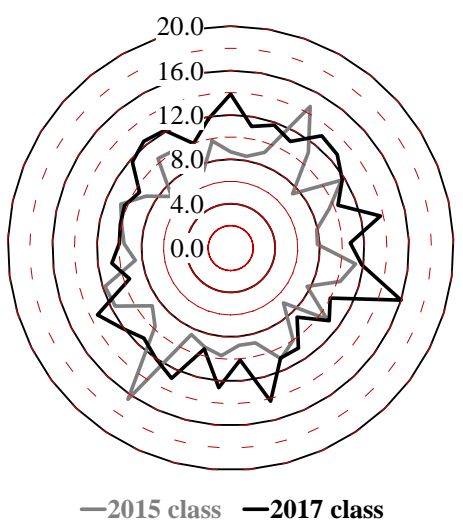

The 2017 class followed the method of reversing teaching forms

b) Groups of more than 30 students

Fig. 4. Comparison between traditional teaching forms and reversing teaching forms

The results for 2017, however, are undeniable and the radar diagram appears balanced. Fluctuations around the average value are much smaller: the standard deviations of the distributions of the 2017 and 2018 cohorts are 1.6 and 1.9, respectively. The students are much less likely to fail, with failure rates for 2017 and 2018 of $14 \%$ and $20 \%$ respectively. For cohorts of equivalent size, the failure rate decreased by nearly $80 \%$ (e.g., nearly $58 \%$ in 2015 and about $14 \%$ in 2017).

Finally, the feedback from the students was very positive and even passionately in favor. In particular, they consider it an "innovative teaching method"; "making the weakest want to get involved"; "making everyone want to contribute to the success of the course"; and "appreciating the fundamental role of the teacher throughout the learning process".

This method offers good prospects for other engineering school specialties. As an example, this approach was tested in 2018 with students in their final year of the mechanics and mechanical engineering specialty at Polytech Tours. The 47 students in this cohort followed the same protocol as described above. Figure 5 shows the distribution of their local grades. The radar diagram clearly shows that the higher the number of students involved, the smoother the results.

As with previous cohorts, the feedback from these students was excellent. They particularly appreciated "the freedom given to students in the acquisition of knowledge and skills"; "making everyone to get involved"; and "highlighting the central role of the teacher in the success of the method". Many of them also expressed the wish that this method should be used in all scientific courses in their engineering curriculum. 


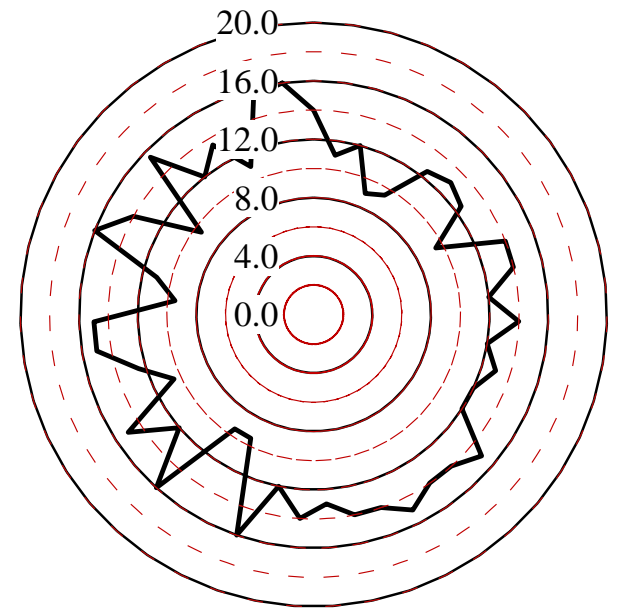

-2018 class in mechanical engineering

Fig. 5. Experimentation of the reversing teaching forms in mechanics and mechanical engineering (2018 class; forty-seven 5th-year University students)

\section{Conclusion}

Gen $\mathrm{Z}$ students are now undertaking university study and bring with them new ways of accessing and processing information. Today, the challenge for teachers is to interest and motivate them. If they are motivated and interested, they will seek to learn by themselves, without anyone pushing them to do so. However, for teachers, this can be a real headache. The deployment of large-scale digital tools, including video used for example in the inverted/flipped classroom model, is interesting, but often takes a lot of time and investment to achieve meaningful results.

This paper describes an approach that is quite simple to implement. It consists of reversing the traditional teaching procedure found in universities, particularly in France. A course begins with practical work, followed by tutorials and finally ends with lectures. The practical work and tutorials are conducted in small groups. In particular, the focus is on increased interaction between students and teachers. From a scientific and technical point of view, the main objective is to visualize physical phenomena in order to better understand them. Finally, the lectures identify inconsistencies in problem solving and methods and guidelines are offered for solving them. Students are also actively involved in the development of these methods of resolution.

This pedagogical approach is particularly well suited to engineering studies.

Feedback from six years of experience is discussed here on the implementation of this method during the final year of a course in a French school of electrical engineering. Two student cohorts followed a traditional university teaching approach (i.e., lectures, tutorials and practical work). The other four student cohorts followed the reverse teaching method. All these student cohorts had the same expectations in terms of the 
skills to be achieved. The various written tests/practical tests/quizzes given to them were of an equivalent level.

The results described in this article demonstrate that this pedagogical approach is both relevant and extremely positive. The method makes it easier to smooth out significant variation in student levels and significantly reduces failure rates. The results of various satisfaction surveys undertaken show that the engineering students fully appreciate the proposed learner-centered pedagogical approach. They also point out that this approach allows teachers to maintain a central role as facilitators of the process. All these results, both quantitative and qualitative, should encourage teachers to modify their approach in order to better prepare future engineers for an increasingly demanding professional environment.

\section{$6 \quad$ References}

[1] Murray M., Pérez J. (2015). Informing and Performing: A Study Comparing Adaptive Learning to Traditional Learning. Informing Science: The International Journal of an Emerging Transdiscipline, 11, pp. 111-125. https://doi.org/10.28945/2165

[2] Hills P. J. (2018). The Self-Teaching Process in Higher Education. New York, USA: Routledge Revivals Taylor and Francis Group.

[3] Yue X. Y. (2019). Exploring Effective Methods of Teacher Professional Development in University for 21st Century Education. International Journal for Innovation Education and Research, Vol. 7, No 5. https://doi.org/10.31686/ijier.vol7.iss5.1506

[4] Ashour S. (2019). How technology has shaped university students' perceptions and expectations around higher education: an exploratory study of the United Arab Emirates. Studies in Higher Education. https://doi.org/10.1080/03075079.2019.1617683

[5] Rajabion L. (2018). Generation Z Students: Will They Change Our Computer Science and IT Classrooms? Systemics, Cybernetics and Informatics, Vol. 16, No 4.

[6] Esteves M. D., Pereira A., Veiga N., Vasco R., Veiga A. (2018). The Use of New Learning Technologies in Higher Education Classroom: A Case Study. International Journal of Engineering Pedagogy, Vol. 8, No 2. https://doi.org/10.3991/ijep.v8i2.8146

[7] Bishop J. L., Verleger M. A. (2013) The Flipped Classroom: A Survey of the Research, American Society for Engineering Education, available via http://www.asee.org/file server/ papers/attachment/file/0003/3259/6219.pdf. Accessed on 10 November 2019.

[8] Samuel M. L. (2019). Flipped pedagogy and student evaluations of teaching. Active Learning in Higher Education. https://doi.org/10.1177/1469787419855188

[9] Flogie A., Aberšek B. (2019) The Impact of Innovative ICT Education and AI on the Pedagogical Paradigm. Newcastle upon Tyne, UK: Cambridge Scholars Publishing.

[10] Anderson L. W., Krathwohl D. R. (2001) A taxonomy for learning, teaching, and assessing: A revision of Bloom's taxonomy of educational objectives. New York, USA: Addison-Wesley Longman.

[11] Filipenko M., Naslund J.-A. (2016) Problem-Based Learning in Teacher Education. Switzerland: Springer International Publishing.

[12] Huening F., Hillgaertner M., Reke M. (2019). Rolling Labs - Teaching Vehicle Electronics from the Beginning. International Journal of Engineering Pedagogy, Vol. 9, No 1. https://doi.org/10.3991/ijep.v9i1.9241 
[13] Jacques S. (2017). A Pedagogical Intensive Collaborative Electric Go-Kart Project. International Journal of Engineering Pedagogy, Vol. 7, No 4. https://doi.org/10.3991/ ijep.v7i4.7408

[14] Castelan J., Bard R. D. (2018). Promoting PBL Through an Active Learning Model and the Use of Rapid Prototyping Resources. International Journal of Engineering Pedagogy, Vol. 8, No 4. https://doi.org/10.3991/ijep.v8i4.8281

[15] Aleryani A. Y., AlMunifi A. A. (2019). A Roadmap to the Development of Key Competencies of Engineering and Technology Graduates. International Journal of Engineering Pedagogy, Vol. 9, No 5. https://doi.org/10.3991/ijep.v9i5.11094

[16] Halverson L. R., Spring K. J., Huyett S., Henrie C.R., Graham C.R. (2017) Blended Learning Research in Higher Education and K-12 Settings. In: Spector M., Lockee B., Childress M. (eds) Learning, Design, and Technology. Springer, Cham. https://doi.org/10.1007/978-3319-17727-4_31-1

[17] Electronics \& Electrical Energy Systems in French, College of Engineering of the University of Tours (France), available via https://polytech.univ-tours.fr/programs/training-of-engineers/electronics-electrical-energy-systems/. Accessed on 10 November 2019.

\section{$7 \quad$ Authors}

Sébastien Jacques received the Ph.D. degree in electronic engineering from the University of Tours (France) in 2010. He has been an Assistant Professor in the Electronics and Energy Department at the College of Engineering of the University of Tours since 2012. He has also been with the research group on materials, microelectronics, acoustics and nanotechnology (GREMAN, CNRS, INSA Centre Val-de-Loire, and UMR 7347). His teaching and research activities focus on power systems and their reliability dedicated to smart cities and, above all, to smart electric mobility. In parallel with all these activities, he is interested in the implementation of innovative teaching methods. Email: sebastien.jacques@univ-tours.fr

Thierry Lequeu obtained in 1991 a high qualification for teaching at the ENS Cachan (France) under the name of "aggregation" in electrical engineering. He received a Master degree in electrical engineering from Centrale Lyon (France) in 1992. Finally, he received the Ph.D. degree in electrical engineering from the University of Marseille (France) in 1996. He has been working at the University of Tours (France) as a Senior Lecturer since 1996. His teaching and research activities are related to the conversion and management of electrical energy. In many power electronics projects, he has focused on the development of electric go-karts as multidisciplinary educational applications.

Article submitted 2019-11-19. Resubmitted 2020-01-04. Final acceptance 2020-01-04. Final version published as submitted by the authors. 